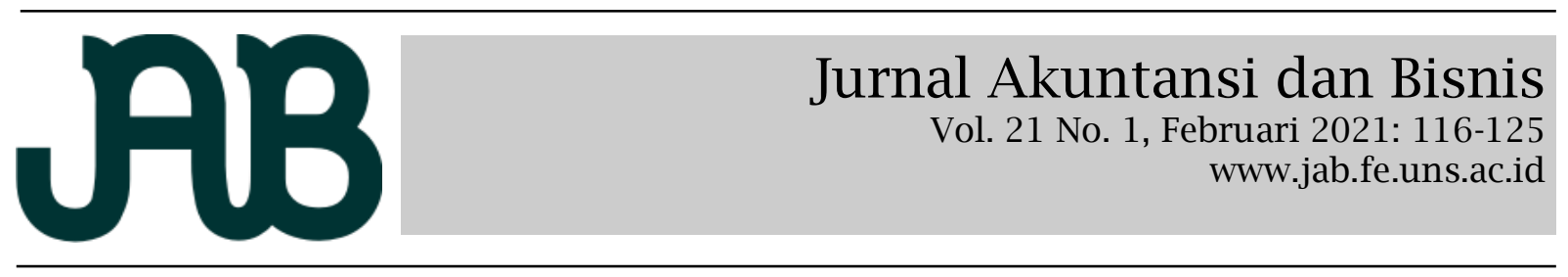

\title{
PENGARUH CEO DAN CFO YANG MEMILIKI PENGALAMAN SEBAGAI AUDITOR TERHADAP KUALITAS LAPORAN KEUANGAN
}

\author{
SIGIT SETYA WICAKSONO \\ MOHAMMAD NASIH (mohammadnasih2021@gmail.com)
}

Departemen Akuntansi, Fakultas Ekonomi dan Bisnis, Universitas Airlangga

\begin{abstract}
A B S T R A C T
The CEO and CFO's experience as auditors has a significant impact on financial reporting. This study describes the experience with the CEO and CFO experience as auditors or partners in an accounting firm. This study was conceived to find out how the CEO and CFO's experience as auditors relate to the quality of the company's financial statements. The study was conducted on non-financial companies listed on IDX in 2014-2018 and a sample of 1993 companies. The researcher uses multi-linear analysis using STATA 14 software to test whether earnings management is related to the variables mentioned above. The results show that CEOs experienced with auditors impact earnings management, while CFOs experienced with auditors do not influence earnings management.

Keywords: quality of financial statements, profit management, CEO, financial manager, accounting efficiency

Pengalaman CEO dan CFO sebagai auditor memiliki pengaruh penting dalam penyusunan laporan keuangan. Pengalaman dengan variabel ini dibuktikan dengan riwayat kerja CEO dan CFO yang pernah menjadi auditor atau rekanan di kantor akuntan publik. Peneliti mencoba untuk menyelidiki hubungan antara CEO dan CFO yang memiliki pengalaman sebagai auditor dan dampaknya terhadap kualitas laporan keuangan perusahaan. Penelitian dilakukan pada perusahaan non-keuangan yang terdaftar di BEI periode 2014-2018 dengan sampel sebanyak 1993 perusahaan. Penulis menggunakan analisis linier berganda dengan menggunakan software STATA 14 untuk menguji apakah manajemen laba berhubungan dengan variabelvariabel di atas. Hasil penelitian menunjukkan bahwa CEO yang berpengalaman sebagai auditor berpengaruh terhadap manajemen laba, sedangkan CFO yang berpengalaman sebagai auditor tidak berpengaruh terhadap manajemen laba.

Kata kunci: kualitas laporan keuangan, manajemen laba, CEO, manajer keuangan, efisiensi akuntansi
\end{abstract}

\section{PENDAHULUAN}

Kasus Enron dan kasus yang akhirnya melanda Worldcom membuka mata dunia luas bahwa perusahaan besar tidak serta merta mampu mempertahankan minat mereka yang konstan. Ketidakmampuan ini merupakan salah satu indikasi bahwa manajemen tidak mampu mengelola sumber daya yang ada atau terindikasi telah melakukan tindakan fraud. Salah satu bentuk kecurangan yang sering dilakukan oleh badan usaha adalah manajemen laba. Beberapa manajemen laba yang sering diterapkan adalah memfasilitasi pendapatan, taking a bath, menambah atau mengurangi pendapatan melalui kelonggaran dalam standar melalui pilihan metode atau kebijakan akuntansi yang ada (Wedari, 2014).

Laporan keuangan yang berkualitas tinggi merupakan kebutuhan yang esensial, terutama sebagai akibat dari kasus-kasus fraud. Pengetahuan tentang akuntansi dan praktik keuangan yang luas adalah suatu keharusan untuk menghasilkan laporan keuangan yang andal. Melalui laporan keuangan ini, media, perusahaan, dan pihak-pihak yang berkepentingan dapat dihubungkan. Namun, jumlah perusahaan yang disebut-sebut melakukan manipulasi laporan keuangan dengan memanipulasi keuntungannya terus bertambah sehingga harus melakukan reformulasi. Aier, Comprix, Gunlock \& Lee (2005) mengutip 
penelitian yang dilakukan oleh General Accounting Office (GAO) pada tahun 2002 yang menyatakan bahwa perusahaan yang dikenai otorisasi ulang meningkat dari 102 pada tahun 1997 menjadi 229 pada tahun 2001. Laba sering digunakan sebagai acuan dalam pengambilan kebijakan untuk pihakpihak yang berkepentingan mulai dari menghitung pajak yang harus dibayar, mengevaluasi kinerja manajemen, dan membagikan penghargaan kepada karyawan. Hal-hal tersebut mendorong para pihak dalam manajemen perusahaan untuk menerapkan manajemen laba dalam laporan keuangannya.

Praktik kecurangan ini tentu bukan inisiatif yang bisa dilakukan oleh karyawan tingkat bawah, tetapi harus ada elit perusahaan yang terlibat di dalamnya. Pihak eksekutif ini dapat memberikan pengaruh dan kekuasaan atas arah kebijakan akuntansi yang diambil oleh perusahaan. Misalnya Bernard Ebers sebagai Chief Executive Officer (CEO) Worldcom dan Scott D. Sullivan sebagai Chief Financial Officer (CFO) Worldcom. Kenneth L. Eyre et al. (2005) menjelaskan bahwa manajer keuangan mungkin memiliki fungsi yang paling penting dalam menghasilkan laporan keuangan yang berkualitas tinggi, dan ini tidak lepas dari peran manajer keuangan yang umumnya memiliki tanggung jawab untuk mengawasi akuntansi dan keuangan perusahaan. Secara khusus, manajer keuangan memantau pelaksanaan aturan dan prosedur akuntansi hingga penyusunan laporan keuangan. Kualitas pelaporan keuangan manajer keuangan juga dapat dipengaruhi oleh kepekaannya terhadap keahlian staf akuntansi perusahaan, respons manajer keuangan terhadap pengendalian internal yang ada, dan pelaporan kepala keuangan atas segala hal yang berkaitan dengan perusahaan kepada senior dan eksternal. CFO memainkan peran besar dalam memengaruhi kualitas pelaporan keuangan, tetapi CEO juga bukan tanpa peran. CFO dan CEO masingmasing memiliki peran mereka sendiri (Feng, Ge, Luo \& Shevlin, 2011). Meskipun CEO tidak berkontribusi secara langsung ketika menyusun laporan yang ada sebagai CFO, temuan penelitiannya menunjukkan bahwa CEO menekan CFO untuk melakukan manipulasi akuntansi material untuk memenuhi dan bahkan melebihi ekspektasi pasar. Penelitian ini juga serupa dengan dilakukan Demerjian, Lev, Lewis \& McVay (2013) menyebutkan jika ada hubungan positif antara kemampuan manajerial dan kualitas laba perusahaan, sebab semakin tinggi kemampuan manajer, semakin tinggi pula kemampuannya dalam memperkirakan nilai akrual perusahaan. Berbeda dengan Aier et al. (2005) yang menjelaskan jika entitas yang mempunyai CFO dengan keahlian akuntansi memiliki penyajian kembali yang lebih sedikit, serupa dengan penelitian Albrecht, Mauldin \& Newton (2018) menunjukkan ketidak adanya hubungan antara tingkat salah saji (misstatement) laporan keuangan perusahaan dengan tingkat perusahaan yang memiliki CEO dan CFO yang berpengalaman sebagai auditor. CEO dan CFO yang berpengalaman sebagai auditor memiliki dapat dikatakan mempunyai dampak negatif atas praktik manajemen laba, sebab salah saji mengindikasikan adanya tindakan agresif para manajer puncak dalam melakukan manajemen laba, dengan minimnya penelitian yang membahas mengenai sepak terjang CEO dan CFO yang memiliki pengalaman sebagai auditor terhadap kualitas laporan keuangan perusahaan, maka hal ini menjadi motivasi kami untuk menulis penelitian ini di Indonesia, dengan karakteristik CEO yang bermacam-macam (Harymawan, Nasih, Agustia, Ratri \& Nowland, 2020).

Berdasarkan latar belakang di atas, peneliti mencoba menemukan bukti empiris bahwa CEO dan CFO yang memiliki pengalaman sebagai auditor berdampak pada kualitas laporan keuangan. Penulis juga berharap penelitian yang dilakukan dapat meningkatkan pemahaman tentang praktik akuntansi, khususnya yang berkaitan dengan analisis laporan keuangan yang dipublikasikan dan pentingnya integritas bagi auditor dalam mengevaluasi laporan keuangan sebagai produk yang dihasilkan oleh CEO dan CFO. Pada bagian selanjutnya, tulisan ini akan menjelaskan pendekatan yang digunakan dalam penelitian ini dengan menggunakan 
pendekatan pendekatan kuantitatif. Data dalam penelitian ini adalah data kuantitatif yang diperoleh dari BEI dengan populasi pengguna yaitu seluruh perusahaan nonkeuangan tahun 2014-2018, karena data laporan keuangan tersebut merupakan laporan dari 5 tahun yang terbaru pada saat penelitian ini ditulis dan industri keuangan memiliki karakteristik perlakuan akuntansi yang berbeda. Analisis data yang dilakukan dalam penelitian ini dirancang dengan menggunakan analisis regresi linier berganda dan dilanjutkan dengan pembahasan hasil pengujian yang dilakukan.

\section{TINJAUAN PUSTAKA DAN PENGEM- BANGAN HIPOTESIS \\ Kualitas Laporan Keuangan}

Potret dari bentuk pertanggungjawaban manajer atas aset yang dikelolanya dan menunjukkan derajat kesuksesan entitas saat melaksanakan operasi bisnisnya selama suatu periode berjalan adalah berupa laporan keuangan. Laporan keuangan juga menjadi alat untuk mengukur tingkat kualitas perusahaan. Jika laporan keuangan entitas yang memuaskan maka dapat dibilang entitas tersebut menjalankan usahanya dengan baik dan bebas dari penyimpangan maupun kecurangan. Emilda (2014) juga menjelaskan hal serupa, bahwa kualitas laporan keuangan yang bagus adalah ketika informasi yang ditampilkan di laporan tersebut berlaku secara umum, dapat digunakan dalam analasis pengambilan keputusan, terbebas dari salah saji, terbebas dari informasi menyesatkan, dan mampu di komparasikan dengan periode sebelumnya.

\section{Manajemen Laba (Earnings Management)}

Dasar pengukuran praktik dari manajemen laba dapat memiliki komponen yang terdiri dari discretionary accruals dan nondiscretionary accruals. Discretionary Accrual (DA) adalah metode yang dapat dikontrol dan dipilih oleh manajemen seperti pemilihan kebijakan metode dan pemilihan estimasi akuntansi yang dipakai. Non -Discretionary Accruals (NDA) adalah praktik akrual yang tidak dapat dikontrol dan dipilih oleh manajer karena efek dari kon- disi ekonomi. Berdasarkan asumsi tersebut DA bisa digunakan untuk proksi maupun ukuran saat menilai ada tidaknya praktik manajemen laba oleh entitas karena manajemen mampu mengendalikannya. Oleh karena itu, penelitian ini nantinya akan menggunakan model modified jones dalam Dechow, Sloan \& Sweeney (1995) untuk menghitung besarnya $D A$.

\section{Pengalaman Auditor}

Proses belajar dan meningkatnya potensi tingkah laku yang didapat melalui pendidikan formal ataupun non-formal akan mengantarkan seseorang kepada tingkah pola laku yang lebih baik inilah yang disebut dengan pengalaman. Shiah-Hou (2021) menjelaskan seseorang yang memiliki pengalaman kerja akan mampu lebih dalam dan lebih luas dalam meng-cover pekerjaannya. Semakin rutin dan intens sesorang melakukan pekerjaan yang berulang, akan meningkatkan keterampilan dan menjadikan seseorang tersebut lebih cepat dalam menyelesaikan tugasnya. Seseorang dengan pekerjaan yang bervariasi juga akan memiliki pengalaman yang semakin luas dan otomatis meningkatkan kinerjanya. Menurut Hamdani (2012) pengalaman yang dimiliki auditor diperoleh dari proses audit dan pemeriksaan yang telah dilakukannya secara berulang di masa lampau. Dan dapat disimpulkan bahwa pengalaman auditor tidak lepas dari tingginya jam terbang serta banyaknya tugas yang pernah dipegang selama melakukan audit atas laporan perusahaan.

Berdasarkan Jensen \& Meckling (1976) menjelaskan teori keagenan sebagai kontrak kerja dari pihak principal (pemegang saham) untuk mempekerjakan pihak agent (manajer) dalam mengurus sumber daya yang dimiliki principal (pemegang saham). Teori keagenan mengasumsikan bahwa adanya perbedaan kepentingan yang timbul atara pemegang saham dan manajer. Dengan kewajibannya manajer perusahaan yang menjalankan operasional perusahaan mempunyai informasi tentang operasi dan kinerja perusahaan secara riil dan menyeluruh dapat menentukan strategi supaya laporan keuangan yang telah diaudit tetap menunjuk- 
kan kinerja perusahan baik sehingga dapat meyakinkan pemegang saham bahwa manajer perusahan telah melakukan pekerjaannya dengan baik yang kemudian manajer bisa mendapatkan insentif berdasarkan kontrak antara pemegang saham dan manajer dan juga dapat meningkatkan reputasi manajer untuk ke depannya.

Pernyataan tersebut didukung dengan penelitian Aier et al. (2005) dan Alzeban (2020) bahwa perusahaan yang memiliki CFO dengan keahlian akuntansi memiliki penyajian kembali atas salah saji yang lebih sedikit, sedangkan Demerjian et al. (2013) menjelaskan bahwa semakin tinggi kemampuan manajer, semakin tinggi pula kemampuannya dalam memperkirakan nilai akrual perusahaan.

Berdasarkan uraian di atas, maka hipotesis yang diajukan dalam penelitian ini, yaitu:

H1: CEO yang memiliki pengalaman sebagai auditor berpengaruh terhadap kualitas laporan keuangan perusahaan.

H2: CFO yang memiliki pengalaman sebagai auditor berpengaruh terhadap kualitas laporan keuangan perusahaan.

\section{METODE PENELITIAN \\ Definisi Operasional dan Pengukuran Variabel \\ Pengalaman auditor CEO}

Pengalaman auditor merupakan kemampuan yang dimiliki seseorang untuk belajar dari kejadian-kejadian masa lalu yang berkaitan dengan seluk-beluk proses pemeriksaan atau pengauditan (Hamdani, 2012). Variabel ini dilambangkan dengan CEO. Variabel ini akan diukur memakai variabel dummy, dengan memberikan nilai 1 ketika CEO perusahaan memiliki pengalaman sebagai auditor baik KAP maupun di BPK, dan 0 untuk sebaliknya.

\section{Pengalaman Auditor CFO}

Menurut Tuahta (2010) pengalaman audit ditunjukkan dari segi lamanya waktu, maupun frekuensi banyaknya penugasan yang pernah dilakukan dalam melakukan proses pemeriksaan atau pengauditan laporan keuangan. Variabel ini dilambangkan dengan CFO. Variabel ini akan diukur memakai variabel dummy dengan mem- berikan nilai 1 ketika CFO perusahaan memiliki pengalaman sebagai auditor baik KAP maupun di BPK, dan 0 untuk sebaliknya.

\section{Kualitas laporan keuangan}

Laporan keuangan merupakan gambaran dari kinerja perusahaan serta bentuk pertanggungjawaban manajer atas aset yang dikelolanya selama suatu periode berjalan. Berdasarkan asumsi ini manajemen laba dapat dijadikan sebagai landasan dalam menentukan kualitas laporan keuangan. Earning management (EM) sendiri adalah bentuk dari perilaku manajer dalam memutuskan kebijakan akuntansi guna menggapai tujuan tertentu. Manajer sebagai pihak yang mengelola perusahaan diberikan kebebasan untuk mengatur perusahaan termasuk keuangan perusahaan sehingga bisa melakukan berbagai upaya agar dapat mencapai target yang diinginkan. Pada penelitian ini untuk mengukur manajemen laba diproksikan menggunakan nilai absolut discretionary accruals (DAC). Discretionary accruals akan dikalkulasi menggunakan Modified Jones Model.

Modified Jones Model merupakan modifikasi dari model Jones yang didesain untuk mengeliminasi kecenderungan untuk menggunakan perkiraan yang bisa salah dari model Jones untuk menentukan DA ketika discretion melebihi pendapatan. Permodelan seperti ini lumrah dipakai pada penelitian di sektor akuntansi disebabkan permodelan ini adalah yang terbaik guna mendeteksi adanya manajemen laba serta menghasilkan hasil paling robust (Sulistyanto, 2008).

Discretionary accrual dengan model ini dikalkulasi melalui tahap-tahap berikut ini:

1. Menghitung nilai total akrual menggunakan rumus sebagai berikut:TAC"it"= $=\Delta$ CA"it"- $\Delta$ CASH"it"- $\Delta$ CL"it"$\triangle$ DCL"it"-DEP"it"

2. 2. Menghitung nilai akrual yang diestimasi menggunakan persamaan regresi linear berganda yang berbasis Ordinary Least Square (OLS) dengan rumus berikut ini: TAC"it" /TA"it-1" = $\beta$ "1"1/TA"it$1 "+\beta " 2 " \Delta$ REV"it" /TA"it-1" + $\beta$ "3"PPE"it" / TA"it-1" +e 
3. Menghitung nilai non-discretionary accruals (NDA) dengan memasukkan nilai koefisien yang telah didapat dari hasil regresi di atas dengan rumus berikut ini: $\quad$ NDAC"it" $=\quad \beta " 0 \quad "+\beta " 1 " 1 /$ TA"it-1" $+\beta " 2 "(\triangle \mathrm{REV} "$ it" $\quad-\triangle \mathrm{REC} "$ it")/TA"it-1" $+\beta " 3$ "PPE"it" /TA"it-1"

4. Menghitung discretionary accrual (DAC) dengan rumus sebagai berikut:DAC"it"= TAC"it" /TA"it-1" - NDAC"it"

\section{Populasi dan Sampel}

Pada penelitian yang dilakukan saat ini populasi yang digunakan adalah perusahaan non-keuangan yang tercatat dari IDX dan OSIRIS pada periode tahun 2014-2018. Dari total 2.690 emiten, jumlah perusahaan menyusut menjadi hanya 1.993 emiten dikarenakan terdapat beberapa perusahaan yang memiliki kode SIC 6 dan data perusahaan yang missing sehingga perusahaan tersebut harus dieliminasi. Variabel- variabel yang diamati pada penelitian ini adalah pengalaman auditor CEO dan CFO sebagai variabel independen, serta kualitas laporan keuangan sebagai variabel dependen.

Pada penelitian ini penulis menggunakan beberapa uji statistik untuk analisis data, yang pertama menggunakan statistik deskriptif. Menurut Anshori dan Iswati (2019) analisis statistik deskriptif adalah statistik yang berfungsi untuk menganalisis data dengan cara menggambarkan data yang telah terkumpul tanpa bertujuan membuat kesimpulan yang berlaku umum. Dalam statistik deskriptif, data yang disajikan berupa informasi yang berkaitan nilai rata-rata (mean), nilai tengah (median), nilai terendah, nilai tertinggi, dan standar deviasi. Selanjutnya winsorize, dilakukan guna mengatasi dampak dari nilai ekstrim (nilai paling tinggi atau paling rendah) pada penelitian yang

Tabel 1.

Distribusi Sampel Pertahun

\begin{tabular}{cccc}
\hline \multirow{2}{*}{ Tahun } & $\begin{array}{c}\Sigma \text { CEO Berpengalaman } \\
\text { Audit }\end{array}$ & $\begin{array}{c}\Sigma \text { CEO Tidak Berpengalaman } \\
\text { Audit }\end{array}$ & $\Sigma$ Total \\
\hline 2014 & 16 & 346 & 362 \\
2015 & 20 & 353 & 373 \\
2016 & 23 & 358 & 381 \\
2017 & 27 & 389 & 416 \\
2018 & 29 & 432 & 461 \\
TOTAL & $\mathbf{1 1 5}$ & $\mathbf{1 . 8 7 8}$ & $\mathbf{1 . 9 9 3}$ \\
Tahun & $\boldsymbol{1}$ CFO Berpengalaman & $\boldsymbol{\Sigma}$ CFO Tidak Berpengalaman & $\boldsymbol{\Sigma}$ Total \\
2014 & Audit & Audit & 362 \\
2015 & 86 & 276 & 373 \\
2016 & 90 & 283 & 381 \\
2017 & 105 & 276 & 416 \\
2018 & 116 & 300 & 461 \\
TOTAL & 121 & 340 & $\mathbf{1 . 9 9 3}$ \\
\hline
\end{tabular}

Tabel 2.

Distribusi Sampel Berdasarkan Kode Klasifikasi Industri

\begin{tabular}{clc}
\hline SIC & \multicolumn{1}{c}{ INDUSTRI } & TOTAL \\
\hline 0 & Agrikultur, Kehutanan, dan Perikanan & 75 \\
1 & Pertambangan dan Kontruksi & 304 \\
2 & Manufaktur (1) & 519 \\
3 & Manufaktur (2) & 337 \\
4 & Transportasi, Komunikasi, Listrik, Gas dan Jasa Kebersihan & 341 \\
5 & Perdagangan Grosir dan Eceran & 193 \\
7 & Industri Jasa (1) & 175 \\
8 & Industri Jasa (2) & 49 \\
& TOTAL & $\mathbf{1 . 9 9 3}$ \\
\hline \hline
\end{tabular}


sering dijumpai sepanjang outlier data penelitian. Data pada satuan moneter sering menggunakan model winsorize ini. Dalam penelitian ini terdapat data yang berbentuk satuan moneter, yaitu Total Asset, Total Current Asset, Total Liability, Total Current Liability, Tax Payable dan Depreciation. Peneliti melakukan uji korelasi menggunakan korelasi Pearson, yang digunakan untuk mengukur tingkat ketergantungan serta arah hubungan linier dua variabel acak (vektor real-valued) (Zhou et al., 2016). Pada program STATA awalnya tabel uji korelasi Pearson, penulis harus mengolah lebih lanjut guna mempermudah pemahaman mengenai arah hubungan antar variabel yang ada dalam penelitian ini. Terakhir untuk melihat atau memprediksi hubungan antar variabel digunakan Analisi Regresi Linier Berganda.

Pengujian ini bertujuan untuk memprediksi hubungan antara variabel dependen dan variabel kontrol terhadap variabel dependen variabel independen. Variabel independen pada penelitian ini adalah CEO dan CFO yang berpengalaman menjadi auditor dan variabel dependen penelitian ini adalah kualitas laporan keuangan. Hipotesis penelitian ini akan diuji menggunakan model regresi sebagai berikut:

$\mathrm{EM}(\mathrm{i}, \mathrm{t})=\alpha+\beta$ 1 CEO_(i,t) $+\beta 2$ CFO_(i,t $)+\beta 3$ $\mathrm{BSIZE}+\beta \_4 \mathrm{KAP}+\beta \_5$ FSIZ_ $(\mathrm{i}, \mathrm{t})+\beta \_6$ LEV_(i,t)+ $\beta \_7$ ROA_(i,t)+ $\beta \_8$ YEAR+ _ 9 INDUSTRY+ $e_{-}(\mathrm{i}, \mathrm{t})$

Keterangan: EM= Kualitas Laporan Keuangan; $\alpha$ : Konstanta; $\beta 1-\beta$ : Koefisien Regresi; CEO: CEO berpengalaman menjadi auditor; CFO: CFO berpengalaman menjadi auditor; FSIZE : Ukuran Perusahaan; LEV:
Leverage; ROA: Return on asset; BSIZE: Komposisi Direksi; KAP: Reputasi Auditor; YEAR: Year fixed effect; INDUSTRY: Industry fixed effect; e: Residual Errors

\section{ANALISIS DAN PEMBAHASAN Statistik Deskriptif}

Statistik deskriptif pada penelitian ini merupakan variabel dependen, variabel independen, dan variabel kontrol dengan penjelasan sebagai berikut, CEO yang mempunyai pengalaman sebagai seorang auditor di suatu perusahaan. Rata-rata secara keseluruhan sebesar 0,057, CFO yang mempunyai pengalaman sebagai seorang auditor di suatu perusahaan. Ratarata secara keseluruhan sebesar 0,260, EM mempunyai sebesar 0,190 , nilai mean BSIZE sebesar 4.666, nilai mean FSIZE sebesar Rp 8.723.337.190,000, nilai mean LEV senilai 0,611, nilai mean ROA sebesar 0,053 .

Untuk mengetahui hubungan setiap variabel yang ada, maka perlu melakukan uji korelasi pearson. Tanda bintang ${ }^{*}$ ) pada uji korelasi menunjukkan hasil yang signifikan dan hubungan yang saling memengaruhi. Semakin banyak tanda bintang (*), maka semakin baik hubungan yang ada, terdapat tiga tanda bintang $\left(^{*}\right)$ yang mewakili yakni, *, ** dan $* * *$. Hubungan searah ditunjukkan dengan tanda positif sedangkan hubungan terbalik ditunjukkan dengan tanda negatif.

\section{Analisis Regresi Linier Berganda}

Nilai Adjusted R Square (Adjusted $\mathrm{R}^{2}$ ) dalam penelitian ini sebesar 0,12 . Hal ini berarti 12\% variasi EM dapat dijelaskan oleh variabel CEO dan CFO serta variabel

Tabel 3.

Hasil Uji Deskriptif

\begin{tabular}{lcccc}
\hline & Rata-rata & Nilai Tengah & $\begin{array}{c}\text { Nilai Teren- } \\
\text { dah }\end{array}$ & Nilai Tertinggi \\
\hline CEO & 0,058 & 0,000 & 0,000 & 1,000 \\
CFO & 0,260 & 0,000 & 0,000 & 1,000 \\
EM & 0,194 & 0,140 & 0,002 & 1,000 \\
BSIZE & 4,671 & 4,000 & 2,000 & 16,000 \\
KAP & 0,349 & 0,000 & 0,000 & 1,000 \\
TASSET & 8781937 & 2310536 & 5224 & 344711000 \\
LEV & 0,633 & 0,490 & 0,000 & 22.611 \\
ROA & 0,053 & 0,024 & $-10,744$ & 2,192 \\
\hline
\end{tabular}


kontrol lainnya. Pada penelitian ini jumlah data yang diregresi sebanyak 1,993. Pada tabel tersebut dapat dilihat pada kolom pertama variabel CEO yang berpengalaman sebagai auditor memiliki nilai koefisien regresi sebesar 0,040, nilai uji t sebesar 2,01 dan tingkat signifikan sebesar 0,045. Nilai koefisien regresi sebesar 0,040 ini menandakan bahwa setiap kenaikan 1 poin CEO yang berpengalaman sebagai auditor akan menaikkan nilai EM sebesar 0,040. Lalu dengan nilai uji $t$ sebesar 2,01 serta tingkat signifikan sebesar 0,045 maka dapat disimpulkan bahwa CEO yang berpengalaman sebagai auditor berpengaruh signifikan terhadap EM dan hipotesis $\mathrm{H} 1$ pada penelitian ini diterima. Kemudian pada kolom kedua variabel CFO yang berpengalaman sebagai auditor memiliki nilai koefisien regresi sebesar 0,006, nilai uji t sebesar 0,68 dan tingkat signifikan sebesar 0,49, maka dapat disimpulkan bahwa CFO yang berpengalaman sebagai auditor tidak berpengaruh signifikan terhadap EM dan hipotesis H2 pada penelitian ini tidak dapat diterima atau ditolak. Kolom ketiga yang merupakan penguat hasil dari kolom pertama dan kedua, dengan meregresi CEO dan CFO yang berpengalaman sebagai auditor secara bersamaan menunjukkan bahwa variabel CEO yang berpengalaman sebagai auditor memiliki nilai koefisien regresi sebesar 0,039, nilai uji t sebesar 1.96, dan tingkat signifikan sebesar 0,05, serta variabel CFO yang berpengalaman sebagai auditor memiliki nilai koefisien regresi sebesar 0,004, nilai uji t sebesar 0,46, dan tingkat signifikan sebesar 0,64.

\section{ANALISIS DAN PEMBAHASAN \\ Pengaruh CEO Berpengalaman Auditor Terhadap Kualitas Laporan Keuangan Perusahaan}

Hasil dari regresi OLS sebelumnya membuktikan bahwa CEO yang berpengalaman sebagai auditor berpengaruh positif signifikan terhadap EM dengan nilai signifikan 0,05 sehingga dapat diartikan bahwa CEO dengan pengalamannya sebagai auditor akan semakin berani dalam mengambil kebijakan akuntansi dalam pengelolaan perusahaan dikarenakan dia telah

Tabel 4.

Korelasi Pearson

\begin{tabular}{|c|c|c|c|c|c|c|c|c|}
\hline & EM & CEO & $\mathrm{CFO}$ & BSIZE & KAP & FSIZE & LEV & $\mathrm{ROA}$ \\
\hline EM & 1,000 & & & & & & & \\
\hline \multirow[t]{2}{*}{ CEO } & $0,058^{* * * x}$ & 1,000 & & & & & & \\
\hline & $(0,010)$ & & & & & & & \\
\hline \multirow[t]{2}{*}{ CFO } & 0,012 & $0,104^{* * * *}$ & 1,000 & & & & & \\
\hline & $(0,607)$ & $(0,000)$ & & & & & & \\
\hline \multirow{2}{*}{$\begin{array}{l}\text { BSIZ } \\
\text { E }\end{array}$} & $-0,091^{* * *}$ & 0,023 & $0,140^{\text {**k }}$ & 1,000 & & & & \\
\hline & $(0,000)$ & $(0,313)$ & $(0,000)$ & & & & & \\
\hline \multirow[t]{2}{*}{ KAP } & $-0,123^{n * *}$ & $0,053^{*-*}$ & 0,022 & $0,312^{n+k}$ & 1,000 & & & \\
\hline & $(0,000)$ & $(0,017)$ & $(0,330)$ & $(0,000)$ & & & & \\
\hline \multirow{2}{*}{$\begin{array}{l}\text { FSIZ } \\
\text { E }\end{array}$} & $-0,148^{* * *}$ & 0,032 & $0,100^{* * * *}$ & $0,536^{\text {w** }}$ & $0,393^{\ldots \ldots+x}$ & 1,000 & & \\
\hline & $(0,000)$ & $(0,157)$ & $(0,000)$ & $(0,000)$ & $(0,000)$ & & & \\
\hline \multirow[t]{2}{*}{ LEV } & $0,253^{\ldots+\cdots *}$ & 0,010 & $-0,008$ & 0,014 & $-0,077^{* * *}$ & $-0,119^{* * *}$ & 1,000 & \\
\hline & $(0,000)$ & $(0,649)$ & $(0,713)$ & $(0,525)$ & $(0,001)$ & $(0,000)$ & & \\
\hline \multirow[t]{2}{*}{ ROA } & $-0,155^{* * *}$ & 0,002 & $-0,012$ & 0,024 & $0,097^{\ldots+\cdots}$ & $0,092^{* * * *}$ & $-0,347^{* \cdots *}$ & 1,000 \\
\hline & $(0,000)$ & $(0,943)$ & $(0,599)$ & $(0,288)$ & $(0,000)$ & $(0,000)$ & $(0,000)$ & \\
\hline
\end{tabular}


memahami proses-proses maupun prosedur dalam melakukan pengauditan di suatu perusahaan. Hal ini sejalan dengan penelitian Albrecht et al. (2018) yang menyebutkan jika para manajer puncak perusahaan seperti CEO merupakan pihak yang bertanggung jawab atas kebijakan yang telah ditetapkan, serta pihak yang paling memiliki kemampuan memengaruhi kebijakan akuntansi. Feng et al. (2011) juga menjelaskan terdapat bukti yang konkrit jika CEO memberi tekanan kepada CFO agar melakukan manipulasi akuntansi yang material supaya bisa memenuhi ekspektasi pasar. Latar belakang tindak kecurangan pada laporan keuangan sehingga mengakibatkan salah saji yang dilakukan CEO ini tidak lepas dari keinginan eksekutif untuk mendapatkan bonus atas kinerjanya, penghindaran pemotongan gaji, hingga faktor reputasi pribadi (Albrecht et al., 2018 ; Scott dan O'Brien, 2011). Tentu hal ini menunjukkan bahwa rendahnya kesadaran moral akan praktik good governance di perusahaan. Padahal menurut Thoha (2003) dengan menjadikan moral sebagai landasan dalam menjalankan praktik good governance dalam perusahaan akan menurunkan penyelewengan dan penyalahgunaan wewenang kekuasaan sehingga dapat meningkatkan keterbukaan, akuntanbilitas, dan kontrol sosial oleh masyarakat. Penelitian ini juga menegaskan penelitian Lennox (2005) jika auditor menerima kebijakan akrual 'abnormal' yang lebih besar ketika para eksekutif maupun direksi perusahaan pernah memiliki pengalaman sebagai partner di kantor firma yang sedang mengaudit perusahaan serta menunjukkan auditor cenderung mengeluarkan opini yang lebih wajar atau lebih baik ketika para top management perusahaan memiliki hubungan kerja sama sebelumnya dengan kantor akuntan publik saat ini.

\section{Pengaruh CFO Berpengalaman Auditor Terhadap Kualitas Laporan Keuangan Perusahaan}

Berdasarkan hasil dari regresi OLS sebelumnya membuktikan bahwa CFO yang berpengalaman sebagai auditor tidak berpengaruh terhadap EM karena nilai signifikan yang diperoleh sebesar 0,648 sehingga dapat diartikan bahwa CFO dengan pengalaman auditor akan lebih

Tabel 5.

Hasil OLS Hubungan Pengalaman CEO dan CFO dengan EM

\begin{tabular}{|c|c|c|c|}
\hline \multirow{2}{*}{ VARIABEL } & \multicolumn{3}{|c|}{ EM } \\
\hline & $(1)$ & $(2)$ & (3) \\
\hline \multirow[t]{2}{*}{ CEO } & $0,040^{* * a}$ & & $0,039^{* * *}$ \\
\hline & $(2,01)$ & & $(1,96)$ \\
\hline \multirow[t]{2}{*}{$\mathrm{CFO}$} & & 0,006 & 0,004 \\
\hline & & $(0,68)$ & $(0,46)$ \\
\hline \multirow[t]{2}{*}{ BSIZE } & $-0,003$ & $-0,003$ & $-0,003$ \\
\hline & $(-1,01)$ & $(-1,07)$ & $(-1,06)$ \\
\hline \multirow{2}{*}{ KAP } & $-0,017^{\prime \prime}$ & $-0,015^{*}$ & $-0,017^{*}$ \\
\hline & $(-1,83)$ & $(-1,68)$ & $(-1,81)$ \\
\hline \multirow[t]{2}{*}{ FSIZE } & $-0,012^{\text {*it }}$ & $-0,012^{* * * *}$ & $-0,012^{* * * k}$ \\
\hline & $(-3,16)$ & $(-3,19)$ & $(-3,18)$ \\
\hline \multirow[t]{2}{*}{ LEV } & $0,031^{* * *}$ & $0,031^{* * *}$ & $0,031^{* * *}$ \\
\hline & $(4,81)$ & $(4,83)$ & $(4,83)$ \\
\hline \multirow{2}{*}{ ROA } & $-0,034^{* *}$ & $-0,034^{* * *}$ & $-0,034^{* *}$ \\
\hline & $(-2,49)$ & $(-2,46)$ & $(-2,48)$ \\
\hline \multirow[t]{2}{*}{ _cons } & $0,388^{n+*}$ & $0,395^{* * *}$ & $0,561^{\text {*ass }}$ \\
\hline & $(7,06)$ & $(7,19)$ & $(9,12)$ \\
\hline Year Dummies & Included & Included & Included \\
\hline Industry Dummies & Included & Included & Included \\
\hline$R$-Squared & 0,120 & 0,118 & 0,120 \\
\hline Number of Observation & 1993 & 1993 & 1.993 \\
\hline
\end{tabular}


berhati-hati dalam mengambil kebijakan akuntansi dalam pengelolaan perusahaan. Hal ini sejalan dengan penelitian Aier et al. (2005), Priscilla dan Siregar (2020) mengukur keahlian CFO melalui pengalaman yang dimiliki, mempunyai gelar CPA dan M.B.A. memiliki kemungkinan lebih kecil untuk melakukan penyajian ulang yang menunjukkan laporan keuangan yang telah dibuat handal dan bebas dari salah saji material. Kekhawatiran bahwa semakin tinggi keahlian manajer maka semakin tinggi pula kemampuannya dalam memperkirakan nilai akrual perusahaan dan melakukan praktik manajemen laba seperti pada penelitian Demerjian et al. (2013) tidak terbukti pada penelitian ini. Hasil penelitian ini menggambarkan bahwa CFO telah melakukan tugasnya dengan baik namun karena adanya tekanan dari CEO membuat CFO melakukan manipulasi akuntansi (Feng et al., 2011). Hal ini juga sejalan dengan hasil penelitian Feng (2011) bahwa CEO secara konkrit telah memberi tekanan kepada CFO agar melakukan manipulasi akuntansi yang material agar dapat memenuhi bahkan melebihi ekspektasi pasar. Sehingga dapat dikatakan CEO memiliki pengaruh lebih besar dalam melakukan tindakan manipulatif sesuai dengan hasil penelitian yang dilakukan penulis. Pada dasarnya CFO telah menjalankan tugasnya dengan baik karena latar belakang CFO yang pernah menjadi auditor sudah selayaknya terikat dalam kode etik akuntan publik yang berisi nilai dan norma moral yang memberikan arahan dalam berkomunikasi dengan masyarakat, pelanggan, dan sesama rekan auditor. Kode etik ini juga menjadikan para pemakai laporan keuangan yang telah di audit mendapat keyakinan bahwa laporan tersebut telah melewati sederetan pertimbangan moral dan etis seperti telah dijelaskan dalam standar kode etik auditor (Utami \& Nahartyo, 2013). Diharapkan dengan hasil ini CFO mampu mewujudkan praktik good governance dalam perusahaan sebagai penyelenggaraan manajemen pembangunan yang solid serta bertanggungjawab, melakukan tertib anggaran, penciptaan kerangka hukum dan politis demi terciptanya iklim usaha yang baik (Mardiasmo, 2021)

\section{SIMPULAN}

Penelitian ini menguji pengaruh dan hubungan antara pengalaman sebagai auditor pada CEO dan CFO dengan kualitas laporan keuangan perusahaan. Berdasarkan pengujian yang telah dilakukan penelitian ini menunjukkan bahwa CEO yang berpengalaman sebagai auditor memiliki pengaruh positif signifikan terhadap kualitas laporan keuangan perusahaan dengan proksi EM. Sementara CFO yang berpengalaman sebagai auditor tidak memiliki pengaruh signifikan terhadap kualitas laporan keuangan perusahaan dengan proksi EM.

\section{KETERBATASAN DAN SARAN}

Keterbatasan pada penelitian kali ini hanya mampu mendeteksi pengalaman auditor CEO dan CFO berdasarkan dari profil direksi yang terdapat pada laporan tahunan perusahaan dan belum bisa mendeteksi pengalaman maupun kemampuan audit lain yang dimiliki CEO dan CFO serta hubungan antara CEO dan CFO dengan kantor akuntan publik yang sedang mengaudit.

Berdasarkan hasil penelitian yang telah diuji, maka saran yang dapat diberikan untuk penelitian selanjutnya yaitu menambah cakupan pengamatan dari pengalaman CEO dan CFO, seperti keahlian CEO dan CFO lainnya, serta hubungan CEO dan CFO dengan kantor akuntan publik yang sedang mengaudit. Selain itu, disarankan juga untuk memperbanyak jumlah sampel agar data yang didapatkan lebih akurat. Kemudian kantor akuntan publik diharapkan lebih berhati-hati dan lebih skeptis ketika memberikan jasa audit pada emiten yang mempunyai CEO/CFO dengan background auditor.

\section{DAFTAR PUSTAKA}

Aier, J.K., Comprix, J., Gunlock, M.T., \& Lee, D. (2005). The financial expertise of CFOs and accounting restatements. Accounting Horizons, 19(3), 123-135.

Albrecht, A., Mauldin, E.G., \& Newton, N.J. (2018). Do auditors recognize the potential dark side of executives' ac- 
counting competence? The Accounting Review, 93(6), 1-28.

Alzeban, A. (2020). The impact of audit committee, CEO, and external auditor quality on the quality of financial reporting. Corporate Governance, 20 (2), 263-279.

Anshori, M., \& Iswati, S. (2019). Metodologi penelitian kuantitatif (Ed. 1). Surabaya: Airlangga University Press

Dechow, P.M., Sloan, R.G., \& Sweeney, A.P. (1995). Detecting earnings management. The Accounting Review, 70(2), 193-225.

Demerjian, P.R., Lev, B., Lewis, M.F., \& McVay, S.E. (2013). Managerial ability and earnings quality. The Accounting Review, 88(2), 463-498.

Emilda, I. (2014). Pengaruh kompetensi sumber daya manusia dan penerapan sistem informasi akuntansi keuangan daerah terhadap kualitas laporan keuangan daerah. Jurnal Ekonomi Akuntansi.

Feng, M., Ge, W., Luo, S., \& Shevlin, T. (2011). Why do CFO's become involved in material accounting manipulations? Journal of Accounting and Economics, 51(1-2), 21-36.

Hamdani, Y. (2012). Pengaruh gender, tekanan ketaatan, dan kompleksitas tugas terhadap audit judgment (Studi Pada Kantor Akuntan Publik di Jawa Tengah), (Dissertation) Universitas Muhammadiyah Surakarta, Surakarta.

Harymawan, I., Nasih, M., Agustia, D., Ratri, M.C., \& Nowland, J. (2020). CEO \& CFO education and R\&D investment in Indonesia. Australasian Accounting, Business and Finance Journal, 14 (2), 16-34.
Jensen, M.C., \& Meckling, W.H. (1976). Theory of the firm: Managerial behavior, agency costs and ownership structure. Journal of Financial Economics, 3(4), 305-360,

Lennox, C. (2005). Audit quality and executive officers' affiliations with CPA Firms. Journal of Accounting and Economics, 39(2), 201-231.

Mardiasmo. (2021). Akuntansi Sektor Publik. Yogyakarta: ANDI.

Priscilla, M. \&Siregar, S.V. (2020). The Effect of Top Management Team Expertise on Corporate's Accrual and Real Earnings Management", Barnett, W.A. and Sergi, B.S. (Ed.) Advanced Issues in the Economics of Emerging Markets (International Symposia in Economic Theory and Econometrics, Vol. 27), Emerald Publishing Limited, Bingley, 79-101.

Scott, W.R. dan O'Brien, P.C. (2011). Financial accounting theory ( $6^{\text {th }}$ Ed.). Toronto: Prentice Hall.

Shiah-Hou, S.R. (2021). Powerful CEOs and earnings quality. Managerial Finance, 47(12), 1714-1735.

Sulistyanto, S. (2008). Manajemen laba (Teori \& model empiris): Grasindo.

Utami, I \& Nahartyo, E. (2013). The Effect of Type a Personality on Auditor Burnout: Evidence from Indonesia. Global Journal of Business Research, 5(2), 89 $-102$.

Wedari, L. K. (2014). Analisis pengaruh proporsi dewan komisaris dan keberadaan komite audit terhadap aktivitas manajemen laba pada perusahaan piblik di Indonesia (Dissertation). Universitas Gadjah Mada, Yogyakarta. 